\title{
RELATO, HISTORIA Y MEMORIA
}

\author{
BEATRIZ SARLO \\ Universidad de Buenos Aires \\ Buenos Aires |Argentina \\ beatriz.sarlo@gmail.com
}

Esto sucedió en el pasado: de la primera guerra, afirmó Walter Benjamin, los hombres volvieron enmudecidos. El shock había liquidado la experiencia transmisible y, en consecuencia, la experiencia en sí misma: lo que se vive como shock es demasiado fuerte para "el minúsculo y frágil cuerpo humano". Los hombres mudos no pudieron encontrar una forma para el relato de lo que habían vivido, y el paisaje de la guerra sólo conservaba del pasado las nubes. Benjamin señala con precisión: "las nubes", porque sobre todo el resto había volado el huracán de un cambio, imprevisible cuando las primeras columnas de soldados se encaminaron hacia los campos de las primeras batallas. La memoria invierte en el presente tanto como la historia, pero de manera distinta. Incluso en estos años, cuando ya se ha ejercido hasta sus últimas consecuencias la crítica de la idea de verdad, las narraciones de memoria parecen ofrecer una autenticidad de la que estábamos acostumbrados a desconfiar radicalmente. La suspensión de esa desconfianza tiene, en el caso de las memorias de la represión, causas morales, jurídicas y políticas.

Historia - Ciudad - Baudelaire - Benjamin 


\title{
RELATO, HISTÓRIA E MEMÓRIA
}

\author{
BEATRIZ SARLO \\ Universidad de Buenos Aires \\ Buenos Aires |Argentina \\ beatriz.sarlo@gmail.com
}

Isso aconteceu no passado: da primeira guerra, disse Walter Benjamin, os homens voltaram sem palavras. O choque havia liquidado a experiência transmissível e, consequentemente, a própria experiência: o que é vivido como choque é forte demais para "o minúsculo e frágil corpo humano". Os homens estúpidos não conseguiam encontrar uma maneira de contar o que haviam experimentado e a paisagem da guerra preservou apenas as nuvens do passado. Benjamin aponta precisamente: "as nuvens", porque acima de todo o resto soprou o furacão de uma mudança, imprevisível quando as primeiras colunas de soldados se dirigiram para os campos das primeiras batalhas. A memória investe no presente tanto quanto na história, mas de uma forma diferente. Mesmo nestes anos, quando a crítica à ideia de verdade já foi exercida até às suas últimas consequências, as narrativas da memória parecem oferecer uma autenticidade da qual estávamos acostumados a desconfiar radicalmente. A suspensão dessa desconfiança tem, no caso das lembranças da repressão, causas morais, jurídicas e políticas.

História - Cidade - Baudelaire - Benjamin 
La narración está unida al cuerpo y a la voz. También está unida al viaje, de donde se traen experiencias e ideas, donde se han escuchado otras historias de otros viajeros, alrededor del fuego, como los oyentes de Odiseo, o como los gauchos Cruz y Martín Fierro que lo primero que intercambian, en el comienzo de una amistad, es el relato de sus desdichas; también los apóstoles fueron viajeros enviados al mundo para contar lo visto y vivido. La narración directa, testimonial, en los tres casos, funda el mito y lo acompaña expansivamente. Estas narraciones dieron razón de una experiencia, sin nombre hasta ellas, y que ellas fundaron. No hay narración sin experiencia, pero tampoco hay experiencia sin narración: el lenguaje libera lo mudo de la experiencia, la redime de su inmediatez y la convierte en lo comunicable, es decir lo común. La narración inscribe a la experiencia en una temporalidad que no es la de su acontecer (amenazado desde su mismo comienzo por el pasado y lo irrepetible), sino la de su memoración. Por lo tanto, la narración también funda una temporalidad, que en cada repetición y en cada variante vuelve a actualizarse.

Esto sucedió en el pasado: de la primera guerra, afirmó Walter Benjamin, los hombres volvieron enmudecidos. El shock había liquidado la experiencia transmisible y, en consecuencia, la experiencia en sí misma: lo que se vive como shock es demasiado fuerte para "el minúsculo y frágil cuerpo humano" (Benjamin 1970, 190). Los hombres mudos no pudieron encontrar una forma para el relato de lo que habían vivido, y el paisaje de la guerra sólo conservaba del pasado las nubes. Benjamin señala con precisión: "las nubes", porque sobre todo el resto había volado el huracán de un cambio, imprevisible cuando las primeras columnas de soldados se encaminaron hacia los campos de las primeras batallas. El fin de La montaña mágica y de La marcha de Radetrkey son variaciones sobre la llegada de algo que no se esperaba, una especie de fuerza de redención inversa, que terminó con lo anterior, destruyéndolo radicalmente, sin posibilidad de que sus restos se incorporaran a ningún porvenir. Entonces, los hombres que fueron llevados al teatro donde esa fuerza desplegó su novedad, perdieron la posibilidad de reconocer su experiencia, porque ella les fue completamente ajena; su carácter inesperado (para esos oficiales que avanzaron en uniforme de gala hacia el barro de las trincheras, para esa caballería que iba a enfrentarse con los tanques, después de los desfiles de despedida donde la victoria parecía asegurada para todo el mundo, para todos los contendientes enemigos) provocó que lo nuevo no pudiera ser vivido sino físicamente, en los mutilados, los enfermos, los hambrientos y los millones de muertos.

Sin embargo, algo en la exposición de Benjamin en su clásico ensayo sobre el narrador, expresa no sólo una perspectiva pesimista, sino melancólica, porque lo que se ha retirado como posibilidad no es simplemente el relato, sino la experiencia misma: lo que sucedió en la gran guerra prueba la relación inescindible entre experiencia y relato, por una parte; y también prueba que llamamos experiencia a lo que puede ser puesto en relato, algo vivido que no sólo se padece sino que se transmite. Experiencia y relato son tan inseparables como cualquier otro de esos pares que la teoría construyó a comienzos del siglo XX, significante y significado, las dos caras de un plano. La primera guerra anuló la experiencia (primera culminación de la modernidad técnica, hizo que los cuerpos ya no pudieran comprender, ni sentirse en casa en el mundo donde se movían); sin embargo, varios siglos antes, en la emergencia de la modernidad europea, el narrador del gesto y la voz, como Odiseo, Scheherazade, los apóstoles, comenzó a perder su dominio. 
En esta inflexión del argumento de Benjamin hay que ubicar a la novela europea. Si el Quijote es, desde el romanticismo hasta los formalistas rusos, un texto-insignia, la novela moderna nace bajo el signo de la ironía y del desencanto. Aunque no es mencionado, Lukacs da la clave interpretativa de la novela en términos de desgarramiento de un mundo, donde la desinteligencia entre lo vivido y la comprensión de lo vivido vuelve dramático cualquier acto y su narración. Debilitadas las razones trascendentes que estaban detrás de la experiencia y el relato, toda experiencia se vuelve problemática (es decir no encuentra su significado) y todo relato está perseguido por un momento autorreferencial, metanarrativo, es decir no inmediato. La experiencia se ha desconcertado y también su puesta en discurso: "Ah, ¿̇a quién pedir ayuda? No al ángel, ni a los hombres, y los astutos animales ya se han dado cuenta de que no confiamos ni nos sentimos en casa en el mundo de los significados". Benjamin se refiere a un "enmudecimiento", a partir de que el relato de una experiencia significativa se eclipsó, mucho antes del shock de la guerra y del shock técnico de la modernidad, con el surgimiento de la novela que tomó el lugar de las "formas artesanales" de transmisión, es decir aquellas arraigadas en la inmediatez de la voz, en un mundo donde el peligro rodeaba a la experiencia (la hacía posible), en lugar de habitar en su centro. En el momento en que el riesgo de la experiencia se interioriza (se vuelve subjetividad moderna), el relato de la experiencia se vuelve tan problemático como la posibilidad misma de construir su sentido. Y eso, siglos antes de Flaubert y La educación sentimental.

Cuando la narración se separa del cuerpo, la experiencia se separa de su sentido. Hay una huella utópica retrospectiva en estas ideas, porque dependen de la aceptación de ese momento de plenitud de sentido en el que el narrador sabe exactamente lo que dice, y quienes lo escuchan lo entienden con asombro, pero sin distancia, fascinados, pero nunca desconfiados o irónicos. En ese momento utópico lo que se vive es lo que se relata, y lo que se relata es lo que se vive. Naturalmente, no corresponde a ese momento legendario la nostalgia, sino la melancolía que reconoce su absoluta imposibilidad.

Seguramente por eso, Benjamin abrió otra línea de reflexión, contradictoria con la del texto famoso sobre el narrador. Su teoría de la filosofía de la historia es una reivindicación de la memoria como método reconstructivo del pasado; los llamados "hechos" son un "mito epistemológico", que reifica, anula su posible verdad y los encadena en un relato dirigido por alguna teleología. En la estela de Nietzsche, Benjamin denuncia el causalismo; en la estela de Bergson, reivindica la cualidad psíquica y temporal de los hechos de memoria. El historiador, seguida esta afirmación en todas sus consecuencias, no reconstruye los hechos del pasado (esto equivale a someterse a una filosofía de la historia reificante y positivista), sino que los recuerda, dándoles así su carácter de pasado presente, respecto del cual hay una deuda impaga.

1 “Ach, wen vermögen / wir denn zu brauchen? Engel nicht, Menschen nicht, / und die findigen Tiere merken es schon, / dass wir nicht sehr verlässlich zu Haus sind / in der gedeuteten Welt" (R.M. Rilke, "Die erste Elegie"; trad. BS). 
Benjamin afirmó, entonces, dos cosas que se traban en una contradicción desgarrada. Por un lado, la disolución de la experiencia y del relato que pierde su verdad presencial sostenida por el cuerpo y la voz. Por otro lado, critica el positivismo histórico que reificaría aquello que en el pasado fue experiencia y que la historia ha convertido en "hecho", anulando su relación con la subjetividad. Sin embargo, si se acepta la disolución de la experiencia, ese "hecho" reificado no podría ser sino lo que es: un resto objetivo, de temporalidad y subjetividad inertes. Frente a esto Benjamin se revela, a través del movimiento romántico-mesiánico de la redención del pasado por la memoria, que devolvería al pasado la subjetividad: la historia como memoria de la historia, es decir como dimensión temporal subjetiva. Como sea, si la memoria de la historia es experiencia, subsiste el problema de construir experiencia en una época, la modernidad, que ha erosionado su posibilidad y que, al hacerlo, también ha vuelto frágiles las fuerzas del relato.

Esta aporía no se resuelve, porque las condiciones mismas de redención de la experiencia pasada están en ruinas. El pensamiento se mueve entre un extremo y opuesto, describiendo, por un lado, las imposibilidades y, por el otro, el movimiento mesiánico de la redención. Podría decirse que las aporías de la relación entre historia y memoria se esbozan ya casi completamente en estos textos. Hasta aquí Benjamin.

\section{SE HA ROTO LA CONTINUIDAD, PERO HAN RENACIDO LOS SUJETOS}

"Lo que hacía familiar al mundo ha desaparecido. El pasado y la experiencia de los viejos ya no sirven como referencia para orientarse en el mundo moderno e iluminar el futuro de las jóvenes generaciones. Se ha roto la continuidad de la experiencia” (Le Goff 2002, 34).

Jean-Pierre Le Goff localiza esta ruptura en los años sesenta del siglo XX y la sostiene en argumentos de innovación tecnológica, cultural y moral. Lo que describe como destrucción de la continuidad entre generaciones no proviene de la "naturaleza" de la experiencia, sino de la aceleración del tiempo; no proviene del shock que dejó enmudecidos a los soldados de la primera guerra, privando a lo vivido de relato, y por lo tanto anulándolo, sino de experiencias que ya no se entienden y son mutuamente inconmensurables: los jóvenes pertenecen a una dimensión del presente en la que los saberes y las creencias de sus padres son inútiles. Donde Benjamin señaló la imposibilidad del relato, Le Goff (y antes Margaret Mead) señalaron su intraducibilidad para generaciones diferentes.

Benjamin captó algo propio de la modernidad capitalista en su sentido más específico. Ella afectó las subjetividades hasta enmudecerlas; en ella, sólo el movimiento de redención mesiánica podría sostener el horizonte utópico de una restauración del tiempo histórico por la memoria que quebraría la corteza reificada de los hechos. Quienes sostienen, en cambio, la hipótesis de un cambio en la continuidad de las generaciones, señalan un tipo de incomunicabilidad de la experiencia de carácter diferente. Se trata de la crisis, también moderna, de la autoridad del pasado sobre el presente. Lo nuevo se impone sobre lo viejo por su cualidad intrínseca liberadora. Todo esto es bien conocido desde las vanguardias estéticas de comienzos del siglo XX: lo que ellas sostuvieron para el arte desbordó sobre la vida en las décadas que siguieron. 
En este corte entre lo nuevo y lo viejo no estaba la subjetividad en juego, por lo menos en primer lugar. La crisis de la idea de subjetividad tuvo que ver con otros procesos y posiciones, de gran expansividad más allá del campo filosófico a partir de los años sesenta. El estructuralismo triunfante conquistó territorios desde la antropología a la lingüística, la teoría literaria y las ciencias sociales. Ese capítulo está escrito y lleva por título la "muerte del sujeto". 2 Cuando ese giro del pensamiento contemporáneo parecía completamente establecido, hace dos décadas, se produjo en el campo de los estudios de memoria y de memoria colectiva el principio de un movimiento de restauración de la primacía de esos sujetos expulsados durante los veinte años anteriores. Se abrió un nuevo capítulo, que ahora podría llamarse "la vuelta del sujeto".

En este punto, las últimas décadas han sido optimistas: nuevamente se ha considerado pertinente el relato de la experiencia y proliferan los discursos llamados "no ficcionales" (tanto en el periodismo como en la etnografía social y la literatura): testimonios, historias de vida, entrevistas, autobiografías, recuerdos y memorias, relatos identitarios. ${ }^{3}$ Un movimiento de devolución de la palabra, de conquista de la palabra y de derecho a la palabra se expande reduplicado por una ideología de la "sanación" identitaria a través de la rememoración social o personal. La textura intensamente subjetiva marca la posmodernidad, como la desconfianza o la pérdida de la experiencia marcó los últimos capítulos de la modernidad cultural. Los derechos de la primera persona se presentan como derechos reprimidos, por una parte; y como instrumentos de verdad por la otra. Si son lo segundo, es claro por qué, desde los lugares de autoridad, se desconfiaría de ellos.

Benjamin sostuvo que el shock interrumpía la relación entre experiencia y relato, es decir que aquello que fue posible hasta un momento determinado se volvió imposible, señalando así el carácter irreversible de la intervención capitalista moderna sobre la subjetividad; hoy, en la estela benjaminiana, la restauración del relato se considera posible, pasando por alto precisamente aquello que, en Benjamin, volvía trágica la situación contemporánea. En efecto, la confianza en un "healing identitario" producido por la palabra, se sustrae de la dimensión problemática en que la subjetividad fue localizada desde finales del siglo XIX y abandona, por decirlo rápidamente, no sólo la perspectiva que señala la herida cultural capitalista, sino todas las epistemologías de la sospecha, de Nietzsche a Freud. El sujeto no sólo tiene experiencias, sino que puede comunicarlas, construir su sentido y, al hacerlo, afirmarse como sujeto. La memoria y los relatos de memoria serían una "cura" de la alienación y la cosificación de la experiencia. Si ya no es posible sostener una Verdad, florecen en cambio unas verdades subjetivas cuyo argumento es la rememoración de lo vivido.

A veces resulta sorprendente encontrar en este campo de ideas la convivencia de un deconstruccionismo filosófico "blando" junto con un optimismo identitario que, si bien no restaura la primacía de Aquel Sujeto anterior al siglo XX, construye Sujetos Múltiples, hábiles como Ulises en las

\footnotetext{
${ }^{2}$ Con una perspectiva crítica es, sin embargo, exhaustivo el panorama proporcionado por (Ferry; Renault 1985).

3 Véase: Arfuch (2002) e Arfuch (2003). En ambas obras se encuentra la muy profusa bibliografía sobre el tema. No puede dejar de señalarse el carácter pionero de las investigaciones de Philippe Lejeune sobre el espacio y el pacto autobiográfico, así como los estudios de Georges Gusdorf y Jean Starobinski. Sin embargo, tanto Gusdorf como Starobinski se anticipan a la moda contemporánea y no pertenecen a ella.
} 
escaramuzas para mantener lo que son y cambiarlo, recuperar el pasado y adecuarlo al presente, aceptar lo extranjero como una máscara a la que, en el momento mismo de aceptarla, se la deforma, transforma o parodiza, sostener las contradicciones liberándose, al mismo tiempo, del binarismo, etc. Siguiendo al más brillante de estos teóricos, Homi Bhabha (1994) se relee no sólo escritos incompatibles con estos principios (como sucede con los usos postcoloniales de Gramsci), sino que se los presenta enmarcados en un aparato filosófico de "efecto" deconstructivo que, de ser coherente, no admitiría ninguna positividad en el discurso identitario.

Como sea, las contradicciones teóricas que admiten al mismo tiempo la indecibilidad de una verdad y la verdad identitaria de los discursos de experiencia, plantean problemas no sólo a la filosofía sino a la historia. Y eso es lo que me interesa ahora: ¿qué garantiza la memoria y la primera persona como captación de un sentido de la experiencia en discurso? Después de haber sido sometida a crítica radical, la restauración de la experiencia y de la memoración de la experiencia es un problema que debería volver a plantearse. La intensa subjetividad que marca un estilo posmoderno marca también este campo de estudio. Cuando nadie está dispuesto a aceptar la verdad de una historia (lo que Benjamin denominó los "hechos" reificados) todos parecemos más dispuestos a la creencia en las verdades de unas historias en plural (el plural: esa inflexión del paradigma que ha ganado la más alta categoría ideológica, lo cual es afortunado, pero también se propone como solución verbalista a cualquier cuestión conflictiva).

\section{APOGEO}

A la salida de las dictaduras del sur de América Latina, recordar fue, en efecto, una actividad reconstructiva y de restauración de lazos perdidos o destruidos. Las víctimas o sus representantes (es decir, sus narradores: desde el comienzo, en los años sesenta, los antropólogos o ideólogos que representaron las historias de Rigoberta Menchú o de Domitila) tomaron la palabra.

Desde los ochenta, en la escena internacional, especialmente la europea, se comenzó a escribir un nuevo capítulo, decisivo, sobre el Holocausto. Por una parte, el debate de los historiadores alemanes sobre la solución final; por la otra, los escritos luminosos de Primo Levi, donde sería difícil hallar ninguna afirmación del saber del sujeto en el Lager, y las lecturas de Giorgio Agamben, donde tampoco es posible encontrar una positividad optimista. Todas estas textualidades acompañaron procesos no siempre sorprendentes desde el punto de vista intelectual pero de una repercusión en la esfera pública que, rápidamente, colocó este tema en un lugar muy visible y, en la práctica, produjo una nueva esfera de debate. Es decir que las transiciones democráticas del sur de América coincidieron (en una de esas casualidades que potencian acontecimientos significativos y no pueden ser pasadas por alto) con un nuevo impulso de la producción intelectual y la discusión ideológica europea. Ambos debates se intersectaron de modo inevitable, en especial porque el Holocausto se ofrece como modelo de otros crímenes, modelo equivocadamente planteado, como lo demuestra Hugo Vezzetti (2004). 
Los crímenes de las dictaduras fueron exhibidos en un florecimiento de discursos testimoniales, en primer lugar, porque los juicios a los responsables (como en el caso argentino) exigió que las víctimas dieran el testimonio de lo que habían padecido y de lo que sabían que otros padecieron hasta morir. Tanto en sede judicial como en los medios de comunicación, la indispensable narración de los hechos no fue recibida con sospechas sobre las posibilidades de reconstruir el pasado, salvo por los criminales y sus representantes que atacaron tanto el principio de verdad como el valor judicial probatorio de las narraciones testimoniales. Si se excluye a los culpables, nadie pensó someter a escrutinio metodológico el testimonio en primera persona de las víctimas. Sin duda, hubiera tenido algo de monstruoso aplicar a esos discursos los principios de duda metodológica que se expusieron al comienzo de estas notas. El shock del campo de concentración nunca pareció un obstáculo para construir y escuchar la narración de la experiencia padecida allí. La novedad de esa experiencia, tan fuerte como la novedad de lo padecido en la primera guerra a la que se refirió Benjamin, no fue un obstáculo para la proliferación de discursos. Las dictaduras representaron, en el sentido más fuerte, un quiebre epocal (como la gran guerra); sin embargo, las transiciones democráticas no fueron períodos enmudecidos por la enormidad de esa ruptura. Por el contrario, en cuanto se dieron las condiciones políticas, los discursos comenzaron a circular y demostraron ser indispensables para la restauración de una dimensión jurídica y moral.

La memoria es un bien común, un deber (como se dijo en el caso europeo) y una necesidad jurídica y política. Sobre la aceptación de estos rasgos es bien difícil establecer una perspectiva que se proponga examinar críticamente la narración de las víctimas. Si su verdad tiene que quedar fuera de duda, también su discurso debe permanecer protegido del escepticismo y de la crítica. La confianza en los testimonios de las víctimas es necesaria a la instalación de regímenes democráticos y al arraigo de un principio de reparación y justicia. Ahora bien, esos discursos testimoniales, de todos modos, son discursos y no deberían ser reificados en una cristalización inabordable. Sobre todo porque, en paralelo y construyendo sentidos con los testimonios sobre los crímenes de las dictaduras, emergen otros hilos de narraciones que no están protegidas por la misma intangibilidad ni tienen la misma legitimidad jurídico-moral.

Para decirlo de otro modo: durante un tiempo (no sabemos hoy cuánto) el discurso sobre los crímenes, porque denuncia el horror, tiene prerrogativas precisamente por el vínculo entre horror y humanidad que comporta. Otras narraciones, incluso pronunciadas por las mismas víctimas o sus representantes, que se inscriben en un tiempo anterior al de los crímenes (digamos, los tardíos años sesenta y los primeros setenta del siglo XX para el caso argentino), que suelen aparecer entrelazadas ya porque provengan del mismo narrador, ya porque se sucedan unas a otras, no tienen las mismas prerrogativas y en la tarea de reconstruir la época que las dictaduras clausuraron pueden ser sometidas a crítica. Además, si las narraciones testimoniales son la fuente principal de saber sobre los crímenes de las dictaduras, los testimonios de los militantes, intelectuales, políticos, religiosos o sindicales de las décadas anteriores no son la única fuente de conocimiento; sólo una fetichización de la verdad testimonial podría otorgarles un peso superior al de otros documentos, incluidos los testimonios contemporáneos a los hechos de los años sesenta y setenta. Sólo una confianza ingenua en la primera persona y en el recuerdo de lo vivido pretendería establecer un orden 
presidido por lo testimonial. Sólo una caracterización ingenua de la experiencia reclamaría para ella una verdad más alta. No es menos positivista (en el sentido en que usó Benjamin esta palabra para caracterizar a los "hechos") el privilegio de la experiencia vivida en la narración testimonial que el de la construcción de un relato a partir de otras fuentes. Y si no sometemos las narraciones sobre los crímenes de las dictaduras al escrutinio ideológico, no hay razón moral para pasar por alto este examen cuando se trata de las narraciones sobre los años que las precedieron.

\section{UNA UTOPÍA: NO OLVIDAR NADA}

Paul Ricœur se pregunta, en el estudio que dedica a las diferencias ya clásicas entre historia y discurso, en qué presente se narra, en qué presente se recuerda, y cuál es el pasado que se recupera. El presente de la enunciación es el "tiempo de base del discurso", porque es presente el momento de ponerse a narrar y ese momento queda inscripto en la narración. Eso implica al narrador en su historia y la inscribe en una retórica de la persuasión (el discurso pertenece al modo persuasivo, dice Ricœur). Los relatos testimoniales son "discurso" en este sentido porque tienen como condición un narrador implicado en los hechos, que no persigue una verdad exterior al momento en que ella se enuncia. Es inevitable la marca del presente del acto de narrar sobre el pasado de lo que se narra, precisamente porque, en el discurso, el presente tiene una hegemonía reconocida como inevitable y los tiempos verbales del pasado no quedan libres de una "experiencia fenomenológica" del tiempo presente de la enunciación. ${ }^{4}$

Extendiendo las nociones de Ricœur, puede decirse que la hegemonía del presente sobre el pasado en el discurso es del orden de la experiencia y está sostenida, en el caso del testimonio, por la memoria y la subjetividad. La rememoración del pasado (que Benjamin proponía como la única perspectiva de una historia que no reificara su objeto), no es una elección sino una condición para el discurso, que no escapa de la memoria ni puede librarse de las premisas que la actualidad pone a la enunciación. $\mathrm{Y}$, más que una liberación de los "hechos" cosificados, como deseaba Benjamin, es una atadura, probablemente inevitable, del pasado a la subjetividad que rememora en el presente.

Las narraciones de la memoria suscitan otros problemas. El deseo memorialístico se mueve hacia un horizonte donde radica la ilusión de evitar la dispersión del sentido. Desde la perspectiva de la historia ya no se pretende reconducir todos los acontecimientos a un origen; renunciando a una teleología causal simple, la historia renuncia, al mismo tiempo, a un principio de intelegilibilidad fuerte y, sobre todo, apropiado para la intervención en la esfera pública, donde los viejos discursos de una historia con argumento nítido prevalecen sobre las perspectivas fragmentarias.

Precisamente el discurso de la memoria y las narraciones en primera persona se mueven por el impulso de cerrar los sentidos que se escapan. Frente

\footnotetext{
4 Se sabe que Ricœur retoma y perfecciona las nociones de historia y discurso, propuestas por Benveniste y Weinrich, preocupándose especialmente por considerar la capacidad del relato en desdoblarse en dos temporalidades, la del momento de contar y la del tiempo de lo narrado, capacidad que constituye su dimensión reflexiva original, que lo habilita para exponer una experiencia fictiva del tiempo, por una parte; $y$, por la otra, quedar referido al tiempo en el que se escribe esa experiencia.
} 
a la dispersión del sentido, se busca establecer un sentido en la narración del recuerdo. En el límite, también está operando la utopía de un relato "completo", del cual no quede nada afuera. De allí la inclinación por el detalle y la acumulación de precisiones con las que se crea la ilusión de que algo concreto de la experiencia pasada fue capturado en el discurso. Mucho más que la historia, el discurso es concreto y pormenorizado, a causa de su anclaje en la experiencia recuperada desde lo singular.

El discurso memorialístico tiene la ambición de la autodefensa, la persuasión al interlocutor presente y el reaseguro de una posición en el futuro; precisamente por eso también tiene mucho de actividad reparadora de la subjetividad. Este aspecto es el que subrayan las apologías del testimonio como "sanación" de identidades en peligro. En efecto, tanto la adjudicación de un sentido único a la historia, como la acumulación de detalles, producen un "modo" (para decirlo con el término de Hayden White) realista romántico, en el cual la subjetividad narrante atribuye sentidos a todo detalle por el hecho mismo que ha sido incluido en el relato; y, en cambio, no está obligada a atribuir sentidos ni a explicar las ausencias, como sucede en el caso de la historia. El primado del detalle es un "modo" realista-romántico de fortalecimiento de la identidad del narrador y de la veracidad de su narración.

Hoy, por el contrario, la historia se ubica lejos de la utopía de que su narración puede incluirlo todo. Opera (como la literatura) con elipsis, por razones metodológicas y razones expositivas. Sobre esta cuestión, se define la diferencia entre "individual" y "específico", en el comentario de Ricœur: "Paul Veyne desarrolla la aparente paradoja de que la historia no tiene como objeto el individuo sino lo específico. La noción de intriga nos aleja de toda defensa de la historia como una ciencia de lo concreto. Incluir un elemento en una intriga, implica enunciar algo inteligible y, en consecuencia, específico: 'Todo lo que puede enunciarse de un individuo posee una suerte de generalidad'." (Ricoeur 1991, 304). Lo específico histórico es lo que puede componer la intriga, no como detalle sino como rasgo significativo; no es una expansión descriptiva de la intriga sino un elemento constitutivo sometido a su lógica.

El principio de la elipsis rige lo específico (a diferencia de un recuerdo sin elipsis como el de Funes, el memorioso), porque, como sucede en la literatura, la elipsis es una de las lógicas de sentido de un relato. Susan Sontag, en Regarding the Pain of Others, afirma, contra toda tendencia a pensar a la memoria como impulso de "sanación", que, frente a los restos de la historia (en su caso, las imágenes de masacre) deberíamos confiar menos en la memoria que en las operaciones intelectuales: comprender tanto o más que recordar. La noción de que la intriga, que es lo que da alguna inteligibilidad, no importa cuán problemática, a los hechos reconstruidos, debe mantener su capacidad de control sobre el detalle, tiene ver con este énfasis en la comprensión. Lo contrario obliga a desconfiar del detalle en la medida en que su inclusión en la intriga queda afectada por una proliferación en "modo" realista, es decir verosimilizante e ilusorio. La proliferación del detalle individual cierra ilusoriamente las grietas de la intriga, y la presenta como si ésta pudiera ser, o debiera ser, un todo, algo completo y verdadero porque el detalle lo certifica, sin tener que mostrar su necesidad. Entre detalle individual y relato teleológico hay una relación obvia aunque no siempre visible. Lo que denomino "modo realista-romántico" se adapta perfectamente a estas cualidades de la narración testimonial que, justamente por estar respaldadas por una subjetividad, sostienen el momento identitario de la memoria. 


\section{LA IMAGINACIÓN SALE DE VISITA}

Una línea decisiva de la estética del siglo XX sostiene la necesidad de una ruptura reflexiva con la proximidad de las sensaciones y de la experiencia para que éstas puedan ser representadas. Bertolt Brecht, los formalistas rusos pensaron que el arte puede iluminar aquello que nos rodea de modo más inmediato a condición de que produzca una ruptura por extrañamiento, que desvíe a la percepción de su hábito y desarraigue los sentidos del suelo tradicional identitario. La puesta en cuestión de lo acostumbrado es la condición de un conocimiento de los objetos más próximos, a los que ignoramos precisamente porque permanecen ocultos por la familiaridad que los vela.

"Pensar con una mente abierta, escribe Hannah Arendt, significa entrenar a la imaginación para que salga de visita" (1982, 47). La imagen, referida a la historia, alude a una externidad de la imaginación respecto de su relato. Quien cuenta una historia se enfrenta, ante todo, con una materia que, incluso en el caso de la experiencia propia, se ha vuelto en alguna medida ajena y probablemente incomprensible. Odilio Alves Aguiar, examinando esta dimensión del pensamiento arendtiano, afirma que, en ausencia de la imaginación, "la experiencia pierde su decibilidad y se pierde en el torbellino de las vivencias y de los hábitos repetidos" (Aguiar 2004). La historia puede dar sentido a este torbellino, pero sólo a condición de que la imaginación cumpla su trabajo de externalización y de distancia; se trata no sólo de una cualidad del historiador sino también de quien lo escucha: la imaginación "sale de visita" cuando rompe con aquello que la constituye en proximidad y se aleja para capturar reflexivamente la diferencia. La condición dialógica se establece por una imaginación que, abandonado el propio territorio, va hacia posiciones desconocidas donde es posible que surja un sentido de experiencias desordenadas, contradictorias y, en especial, resistentes a rendirse ante la idea demasiado simple de que se las conoce porque se las ha soportado.

Con la franqueza severa que sólo su condición de víctima volvió audible, Primo Levi sostuvo que el campo de concentración no ennoblece a sus víctimas; podría agregarse que tampoco el horror padecido les permite conocerlo mejor. Para conocer, la imaginación necesita ese recorrido que la lleva fuera de sí misma, y la vuelve reflexiva; en su viaje aprende que la historia nunca podrá contarse del todo y nunca tendrá un cierre, porque todas las posiciones no pueden ser recorridas. El principio de un diálogo sobre la historia descansa en el reconocimiento de su incompletitud (que, por supuesto, no es una falta en la representación del detalle sino una admisión del carácter múltiple de los procesos y de las posiciones). De este modo, la narración así pensada no podría sostener una identidad ni una tradición, tampoco dotar de legitimidad a una práctica. No cumple funciones de fortalecimiento identitario ni de fundación de leyendas nacionales. Permite ver, precisamente, lo excluido de las narraciones identitarias reivindicativas de un grupo o una nación. La óptica de esta historia no es lejana sino desplazada de lo familiar: como lo sugiere Benjamin, es la óptica de quien soporta el desplazamiento del viajero, que abandona el país de origen.

A las narraciones de memoria, los testimonios y los escritos de fuerte inflexión autobiográfica los acecha el peligro de una imaginación que se establece demasiado firmemente "en casa", precisamente porque esa casa se reivindica como una de las conquistas de la empresa de memoria: recuperar aquello perdido por la violencia de un poder, un deseo cuya entera legitimidad 
moral no es suficiente para fundar una legitimidad intelectual igualmente indiscutible. Entonces, si lo que la memoria busca es recuperar un lugar perdido, sería ajena a su movimiento la deriva que la alejara de ese centro utópico.

Esto es lo que vuelve a la memoria, de algún modo, irrefutable: el valor de verdad del testimonio hace valer la inmediatez de la experiencia; y su capacidad de contribuir a la reparación del daño sufrido (un tipo de reparación indispensable en el caso de las dictaduras del sur de América) la localiza en aquella dimensión redentora del pasado que Benjamin reclamaba como deber mesiánico de una historia antipositivista.

Del lado de la historia (si es que pese a todas las heridas, o por ellas justamente, queremos tener una historia, y no escribo la palabra en plural para evitar que un fetichismo gramatical cierre el problema de la multiplicidad de perspectivas), el derecho de veto de la memoria le plantea un desafío. En las últimas décadas la historia se acercó a la memoria y aprendió a interrogarla; la expansión de las "historias orales" y de las microhistorias es suficiente para probar que ese tipo de testimonios ha obtenido una escucha. El "deber de memoria" que impone el Holocausto a la historia europea, fue acompañado por la atención prestada a las memorias de los sobrevivientes y las huellas dejadas por las víctimas.

Si la memoria es un impulso moral de la historia y también una de sus fuentes, estas dos cualidades no soportan el reclamo de una verdad más indiscutible que las verdades que es posible construir con y desde otros discursos. Sobre la memoria no hay que fundar una epistemología ingenua cuyas pretensiones serían rechazadas en cualquier otro caso. No existe un intercambio abstracto entre el derecho a recordar y la afirmación de una verdad del recuerdo; más bien, el pensamiento del siglo XX nos provee de todas las desconfianzas frente al discurso de la memoria ejercido como construcción de verdad del sujeto.

Esto se diferencia, por supuesto, del despliegue de la memoria en la literatura; y, sobre todo, de una "imposición de la memoria" como lo prueba el film Shoab: Claude Lanzmann fuerza a los aldeanos polacos que vivieron cerca del emplazamiento de los campos a que recuerden lo que han olvidado, lo que no quieren recordar, sus propias miserias e indignidades frente a los trenes que pasaban con las víctimas; y también fuerza más recuerdos que los “espontáneos" en los sobrevivientes, los persigue con su cámara hasta que, en algunos testimonios, éstos le piden que dé por terminada la entrevista. Tanto en los aldeanos como en los sobrevivientes, aunque de maneras diferentes, la memoria es exigida más allá de lo que los sujetos pensaron que podía serlo y más allá de sus intereses y voluntades. Así, la memoria del holocausto se descentra, no porque abandone la escena de masacre, sino porque va a ella $a$ pesar de quienes dan su testimonio, o forzando la espontaneidad de su recuerdo. 


\section{¿QUÉ FUE EL PRESENTE?}

La memoria es siempre anacrónica. Los aldeanos a quienes Lanzmann obliga a recordar, con violencia simbólica, responden sobre un tiempo que se ven forzados a traer hasta el presente en el que están respondiendo; lo mismo sucede con los sobrevivientes de los campos de concentración, empujados a ir más allá de lo que recordarían librados sólo a una rememoración espontánea. En ambos casos, el saber que Lanzmann tiene de los campos actúa sobre la memoria de las víctimas o de los testigos para hacerles decir más de lo que dirían. Esa intervención es una forzadura de la "memoria espontánea" de aquel pasado, sobre la que se ejerce una presión con un saber construido en el presente. Los aldeanos o las víctimas también hablan en el presente e, inevitablemente, saben más de lo que sabían en el momento de los hechos, aunque también hayan olvidado o buscado el olvido.

Esta discordancia de los tiempos es inevitable tanto para la historia como para las narraciones testimoniales. También la historia está perseguida por el anacronismo y uno de sus problemas es precisamente reconocerlo y trazar sus límites. Todo discurrir sobre el pasado tiene una dimensión anacrónica; cuando Benjamin se inclina por una historia que libere al pasado de su reificación, redimiéndolo en un hecho presente de memoria, en el impulso mesiánico por el que el presente se haría cargo de una deuda de sufrimiento con el pasado, es decir en el momento en la historia se plantea hacer lo que no puede hacer el ángel de Klee, está poniendo de manifiesto que el presente opera sobre la construcción del pasado y, más aún, que es su deber hacerlo.

El anacronismo benjaminiano tiene una dimensión filosófica y forma parte de una posición polémica respecto del fetichismo documental y antiinterpretativo de la "historia científica" a comienzos del siglo XX. Sin embargo, criticar la cualidad objetiva atribuida a los hechos del pasado, no agota el problema de la doble inscripción temporal de la historia. La indicación de Benjamin podría también ser leída como una lección a historiadores: mirar el pasado con los ojos de quienes lo vivieron, para poder captar allí el sufrimiento y las ruinas. La exhortación sería, en este caso, metodológica y, en lugar de fortalecer el anacronismo, sería un instrumento para disolverlo.

Estas cuestiones de perspectiva se plantean para encarar un problema que, de todos modos, persistirá. La historia no puede simplemente cultivar el anacronismo por elección, porque se trata de una fuerza que la golpea todo el tiempo y está sostenida por su propio proceso de enunciación (se sabe: la enunciación es siempre presente). Lo que sucede es que la historia no está cómoda en esta doble temporalidad de su escritura y de su objeto. Esto la distingue de los procesos que producen las narraciones testimoniales, donde el presente de la enunciación es la condición misma de la rememoración: es su materia temporal, tanto como el pasado es aquella materia temporal que quiere recapturarse. El núcleo del testimonio es la memoria; naturalmente, no podría decirse lo mismo de la historia (en un extremo, alguien podría decir que es preciso hacer historia como si se recordara, lo que sólo abre una condición hipotética).

El testimonio puede ser abiertamente anacrónico, compuesto por lo que un sujeto se permite recordar, lo que olvida, lo que pasa en silencio de modo deliberado, lo que miente y falsifica, lo que cambia de registro y de género discursivo, lo que sus instrumentos culturales le permiten captar del pasado, lo que sus ideas presentes le indican que debe ser enfatizado en función de una acción política o moral en el presente, lo que necesita como 
dispositivo retórico para convencer, lo que necesita para atacar o defender posiciones, etc. etc. La impureza del testimonio es una fuente inagotable de vitalidad polémica y por eso es interesante; pero también requiere que esa heterogeneidad sesgada no se olvide frente al impacto de la primera persona que habla por sí y pone su nombre como reaseguro de su verdad. Tanto como las de cualquier otro discurso, las pretensiones de verdad del testimonio son eso: un reclamo de prerrogativas. Si, en el testimonio, el anacronismo es más inevitable que en cualquier otro género de la historia, ello no obliga a aceptar lo inevitable como inexistente, es decir olvidarlo precisamente porque no es posible eliminarlo.

Cuando me refiero al anacronismo (Sarlo 2003) entiendo el que Georges Didi-Huberman llama "trivial", diferenciándolo de un anacronismo legítimo e, incluso, necesario. Los objetos (en su ejemplo, el fresco de la Madonna de las Sombras, en el convento de San Marcos, Florencia), considerados en la larga duración son "un ensamblaje de anacronismos sutiles, fibras de tiempo entremezcladas, campo arqueológico a descifrar" (DidiHuberman 2000, 36-37). Siguiendo a Jacques Rancière, Didi-Huberman sugiere que estos objetos nos colocan frente a un tiempo que desborda los marcos de una cronología: "Ese tiempo, que no es exactamente el pasado, tiene un nombre: es la memoria.... que humaniza y configura el tiempo, entrelaza sus fibras, asegura las transmisiones, y se condena a una esencial impureza... La memoria es psíquica en su proceso, anacrónica en sus efectos de montaje, de reconstrucción o de 'decantación' del tiempo. No puede aceptarse la dimensión memorativa de la historia sin aceptar, junto a ella, su anclaje en el inconsciente y su dimensión anacrónica" (Didi-Huberman 2000, 36-37). El argumento de Didi-Huberman es convincente cuando se trata de examinar el modo según el cual la interpretación presente se construye, de modo inevitable (y, en consecuencia, lo mejor es que lo sea de manera explícita), con capas de sentidos y de experiencia que son posteriores a los hechos o a los objetos. El caso que él presenta es el de un panel "abstracto" del fresco de Fra Angelico, cuya visión actual no puede prescindir de lo que vino siglos después en la historia del arte, es decir la no figuración. Didi-Huberman no propone, por cierto, ninguna hipótesis inverosímil sobre las tendencias abstractas de Fra Angelico; sólo dice que su visión no puede prescindir de ellas. El panel había resultado invisible a los historiadores del arte, hasta que el tiempo mixto y conflictivo de una visión anacrónica vuelve a hacerlo visible para DidiHuberman. 


\section{CONTRA UN MITO DE LA MEMORIA}

Paolo Rossi escribe que, después de Rousseau, "el pasado será concebido como siempre 'reconstruido' y organizado sobre la base de una coherencia imaginaria. El pasado imaginado se vuelve un problema no sólo para la psicología, sino también (y se debería decir, sobre todo) para la historiografía... La memoria, como se ha dicho, 'coloniza' el pasado y lo organiza sobre la base de las concepciones y las emociones del presente" (Rossi 2003, 87-88). Coloco la cita en el centro de mi argumento. Por un lado, la narración hace sentido del pasado, pero sólo si, como señaló Arendt, la imaginación viaja, se despega de su inmediatez identitaria; todos los problemas de la experiencia (si se admite que hay experiencia, es decir, si se abandona el pesimismo benjaminiano, cuestión que no es sencilla de todas formas) se abren en una actualidad que oscila entre afirmar la crisis de la subjetividad en un mundo mediatizado y la persistencia de la subjetividad como una especie de artesanado de resistencia.

De todos modos, si no se practica un escepticismo radical y se admite la posibilidad de una reconstrucción del pasado, se abren las vías de la subjetividad rememorante y de una historia sensibilizada a ella pero que se distingue conceptual y metodológicamente de sus narraciones. Esa historia, como lo señala Rossi, vive bajo la presión de la memoria (realizando, de modo extremo, lo que Benjamin solicitara como refutación del positivismo reificante) que reclama las prerrogativas de proximidad y perspectiva, prerrogativas a las que la memoria quizás tiene derechos morales, pero no otros. Los discursos de la memoria tan impregnados de ideologías como los de la historia, no se someten como los de la historia a un control que tenga lugar en una esfera pública separada de la subjetividad.

La memoria invierte en el presente tanto como la historia, pero de manera distinta. Incluso en estos años, cuando ya se ha ejercido hasta sus últimas consecuencias la crítica de la idea de verdad, las narraciones de memoria parecen ofrecer una autenticidad de la que estábamos acostumbrados a desconfiar radicalmente. La suspensión de esa desconfianza tiene, en el caso de las memorias de la represión, causas morales, jurídicas y políticas. Pero cuesta concederles a otras narraciones de memoria las mismas cualidades, cuando es evidente que su discurso compite con el de la historia reclamando los privilegios de una subjetividad que sería su garante, como si pudiéramos volver a creer en alguien que simplemente dice: "digo la verdad de lo que sucedió conmigo", colocándose, por el ejercicio de una imaginaria autenticidad testimonial, más allá de la desconfianza crítica en una especie de limbo interpretativo. 


\section{REFERENCIAS}

AGUIAR, Odilio Alvez. Pensamento e Narração em Hannah Arendt. Belo Horizonte: Editorial da UFMG, 2001.

ARENDT, Hannah. Lectures on Kant's Political Philosophy. Chicago: Chicago University Press, 1982.

ARFUCH, Leonor. El espacio biográfico. Dilemas de la subjetividad contemporánea. Buenos Aires: FCE, 2002.

ARFUCH, Leonor. Identidades, sujetos, subjetividades, Buenos Aires, Prometeo Libros, 2003.

BAHBA, Homi K. DissemiNation: time, narrative, and the margins of the modern nation", In: Homi Bhabha (Conp.), Nation and Narration. Londres: Routledge, 1991.

BHABHA, Homi K. The Location of Culture. London: Routledge, 1994.

BENJAMIN, Walter. El narrador. Consideraciones sobre la obra de Nikolai Leskov" In: Sobre el programa de la filosofía futura y otros ensayos. Caracas: Monte Avila, 1970.

DIDI-HUBERMAN. Devant le temps; histoire de l'art et anachronisme des images. París: Minuit, 2000.

FERRY, Luc; La pensé 68. Essai sur lántihumanisme contemporain. Paris: Gallimard, 1985.

LE GOFF, Jean Pierre. Mai 68, l’héritage impossible. París : La Découverte, 2002.

RICOEUR, Paul. Temps et récit, cit., vol. 1: L’intrigue et le récit historique. Paris: Seuil, 1991.

ROSSI, Paolo. Elpasado, la memoria, el olvido. Buenos Aires: Nueva Visión, 2003.

SARLO, Beatriz. La pasión y la excepción. Buenos Aires: Siglo XXI, 2003.

VEZZETTI, Hugo. Pasado y presente. Buenos Aires: Siglo XXI Editores, 2002.

\section{(c)}

Este é um artigo de acesso livre distribuído nos termos da licença Creative Commons Attribution, que permite uso irrestrito, distribuição e reprodução em qualquer meio, desde que o trabalho original seja citado de modo apropriado 